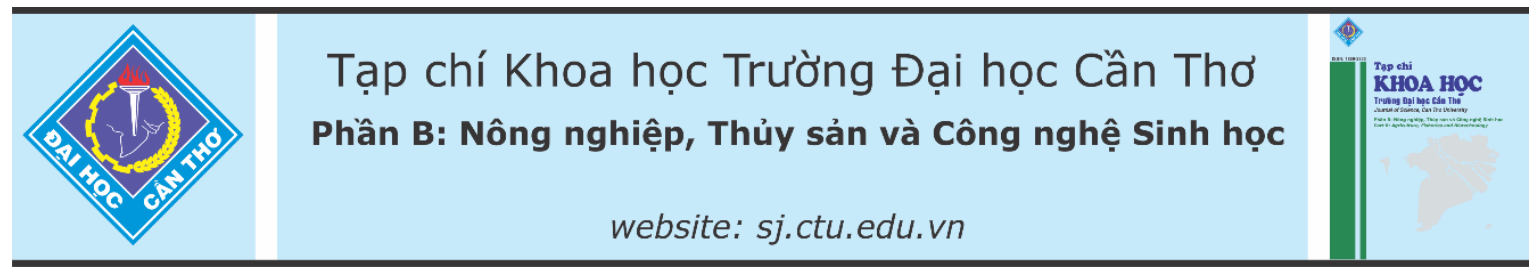

DOI:10.22144/ctu.jvn.2021.040

\title{
KHẢO SÁT THÀNH PHÀ̀ HÓA HỌC VÀ HOẠT TÍNH SINH HỌC CỦA CÁC CAO CHIẾT TÙ XÀ LÁCH XOONG (Nasturtium microphyllum)
}

\author{
Huỳnh Ngọc Trung Dung ${ }^{1 *}$, Nguyễn Phương Thảo ${ }^{2}$ và Nguyễn Phú Lộc ${ }^{3}$ \\ ${ }^{1}$ Khoa Dược - Điều Dương, Trường Đại học Tây Đô \\ ${ }^{2}$ Sinh viên Dược 10C, Trường Đại học Tây Đô \\ ${ }^{3}$ Bộ môn Y họ cổ truyền, Truờng Đại học Y Dược Cần Tho \\ *Nguời chịu trách nhiệm về bài viết: Huỳnh Ngoc Trung Dung (email: hntrungdung@gmail.com)
}

\section{Thông tin chung:}

Ngày nhận bài: 25/10/2020

Ngày nhận bài sưa: $26 / 12 / 2020$

Ngày duyệt đăng: 28/04/2021

Title:

Investigation of chemical composition and bioactivity of one-row watercress extracts

(Nasturtium microphyllum)

\section{Tù khóa:}

Kháng oxy hóa, DPPH,

flavonoid, Nasturtium

microphyllum, polyphenol toàn phần

\section{Keywords:}

Antioxidant, DPPH, flavonoid, Nasturtium microphyllum, total phenolic

\section{ABSTRACT}

In this study, one-row watercress (Nasturtium microphyllum) ethanol (70\% and $96 \%$ ) extracts were determined the total phenolic content (by Folin-Ciocalteau method), flavonoid contents (using aluminium chloride colorimetric method) and evaluated for antioxidant activity estimated by DPPH (2,2-diphenyl-1-picryl-hydrazyl-hydrate). The total phenolic content obtained ranged from $2.72 \pm 0.28$ to $6.01 \pm 0.177 \mathrm{mg} / \mathrm{g}$ GA fresh weight, and the total flavonoids contents resulted from $1.99 \pm 0.307$ to $3.33 \pm 0.049 \mathrm{mg} / \mathrm{g}$ fresh weight in these ethanol $(70 \%, 96 \%)$ extracts. The $I C_{50}$ values for scavenging of free radicals were from $493.40 \pm 0.007$ to $960.83 \pm 0.006 \mu \mathrm{g} / \mathrm{mL}$. Moreover, by using Sulforhodamin B method, at $500 \mu \mathrm{g} / \mathrm{mL}$ concentration, all of one-row watercress ethanol extracts have ability to cytotoxic the breast cancer cell line MCF-7 but relatively low (fresh one-row watercress ethanol $96 \%$ extract has the best cytotoxicity with a toxic percentage is $32.44 \%$ ). At $2,000 \mu \mathrm{g} / \mathrm{mL}$ dry one-row watercress ethanol $96 \%$ extract inhibit $17.52 \%$ the $\alpha$-glucosidase in vitro.

\section{TÓM TẮT}

Trong nghiên cúu này, các cao chiết (ethanol 70\% và 96\%) của cây xà lách xoong (Nasturtium microphyllum) được xác định hàm luọng polyphenol (sủ dụng thuốc thư Folin-Ciocalteau), flavonoid toàn phần (đo màu aluminium chlorid) và đánh giá khả năng khư gốc tụ do DPPH (2,2-diphenyl-1-picryl-hydrazyl-hydrat). Hàm luợng polyphenol toàn phần của các cao chiết dao động tù̀ 2,72 $\pm 0,028$ đến $6,01 \pm 0,177 \mathrm{mg} / \mathrm{g}$ GA trọng lương tuooi, hàm lượng flavonoid toàn phần trong khoảng 1,99 $\pm 0,307$ đến 3,33 $\pm 0,049 \mathrm{mg} / \mathrm{g} Q E$ trọng lương tuooi và khả năng khử gốc tụ do DPPH (2,2-diphenyl-1-picryl-hydrazyl-hydrat) với các IC ${ }_{50}$ trong khoảng 493,40 - 960,83 $\mu \mathrm{g} / \mathrm{mL}$. Bên canh đó, bằng phuoong pháp Sulforhodamin $B$, ở nồng độ $500 \mu \mathrm{g} / \mathrm{mL}$ các cao thử nghiệm thể hiện khả năng gây độc tế bào ung thu vú dòng MCF-7 tuơng đối thấp (cao chiết xà lách xoong tuơi ethanol $96 \%$ có khả năng gây độc tế bào tốt nhất với phần trăm gây độc là 32,44\%). Ở nồng độ $2.000 \mu \mathrm{g} / \mathrm{mL}$ cao chiết xà lách xoong khô ethanol $96 \%$ úc chế đượ 17,52\% a-glucosidase in vitro. 


\section{GIÓ́I THIÊU}

Ngày nay, việc phát triển các loại thuốc và thực phẩm chức năng có tác dụng bổ sung dinh dưỡng và phòng chống bệnh tật ngày càng được quan tâm nghiên cứu và sử dụng, đặc biệt là các sản phẩm có nguồn gốc từ thực vật do khả năng điều trị, tính an toàn, ít tác dụng phụ và có thể dùng trong bữa ăn hằng ngày. Xà lách xoong (Nasturtium microphyllum) là một giống cải do người Pháp du nhập với tên tiếng Pháp là "cresson de fontaine" hoặc cresson à petites feuilles, thường được dùng ăn sống hay nấu chín quen thuộc với đời sống người Việt, tuy nhiên, các nghiên cứu về loại thực vật này hiện nay vẫn còn rất ít. Trên thế giới đã có nghiên cứu về khả năng kháng khuẩn, kháng nấm của xà lách xoong, cụ thể là khả năng kháng các chủng Staphylococcus aureus (dòng PTCC1431), Escherichia coli (dòng HP101BA 7601c), Klebsiella pneumonia, Salmonella typhi, Bacillus subtilis và các chủng nấm: Aspergillus fumigatus, Aspergillus flavus (Imtiaz, 2012; Sepahi, 2014). Mục tiêu của nghiên cứu nhằm xác định hàm lượng polyphenol toàn phần (TPC), flavonoid toàn phần (TFC) có trong cây xà lách xoong, bên cạnh đó, khả năng ức chế $\alpha$-glucosidase và gây độc tế bào ung thu vú (in vitro) cũng được khảo sát nhằm bước đầu đánh giá và bổ sung dữ liệu nghiên cứu về loài cây này trong việc hỗ trợ ngăn ngừa và điều trị bệnh.

\section{VẬT LIỆU VÀ PHƯƠNG PHÁP NGHIÊN CÚU}

\subsection{Vật liệu}

\subsubsection{Nguyên liệu}

Xà lách xoong được thu tại xã Thuận An, huyện Bình Minh, tỉnh Vĩnh Long vào tháng 01 năm 2020. Căn cứ vào đặc điểm hình thái, mô tả của các tài liệu tham khảo (Phạm Hoàng Hộ, 2003; Rasheed et al., 2018) để xác định đúng loài. Mẫu được lưu giữ tại Phòng thí nghiệm Hóa sinh, Khoa Dược-Điều dưỡng, Trường Đại học Tây Đô.

\subsubsection{Thiết bị sử dụng trong nghiên cúu}

Tủ sấy Memmert UN55 (Đức), bếp cách thủy Memmert (Đức), cân phân tích MB27 Ohasu, cân phân tích Ohasu PA 0,001g, máy UV-1800 SHIMADZU, máy ELISA reader (Muliskan FC), máy đo quang Gene Quant 1300.

\subsubsection{Dung môi, hóa chất}

Định luọng Polyphenol: Folin-Ciocalteu (Merck), gallic acid (Sigma), $\mathrm{Na}_{2} \mathrm{CO}_{3}, \mathrm{H}_{2} \mathrm{O}$.

Định luọng Flavonoid: Quercetin (Sigma), $\mathrm{NaNO}_{2} 10 \%, \mathrm{AlCl}_{3} 10 \%, \mathrm{NaOH} 1 \mathrm{M}, \mathrm{H}_{2} \mathrm{O}$.
Khảo sát hoạt tính kháng oxy hóa: Methanol (Xilong), 1,1-dipheny-2picrylhydrazyl (DPPH, Sigma), ascorbic acid (Sigma).

Gây độc tế bào MCF-7: Môi trường Eagle's Minimal Essential Medium (E'MEM), L-glutamin, 4-(2-hydroxyetyl)-1-piperazineethanesulfonic acid (HEPES), amphotericin $\mathrm{B}$, penicillin G, streptomycin, huyết thanh bào thai bò - Fetal bovine serum (FBS), trichloroacetic acid 50\% (Sigma), sulforhodamin B 0,2\% (Sigma).

Úc chế $\alpha$-glucosidase: Chất đối chứng acarbose (Sigma-Aldrich), $\alpha$-glucosidase (Sigma-Aldrich), chất nền $p$-nitrophenyl- $\alpha$-D-glucopyranosid (Sigma-Aldrich).

\subsection{Phương pháp nghiên cứu}

2.2.1. Định tính thành phần hóa học có trong các mẫu xà lách xoong

Mẫu xà lách xoong (tươi, khô) được định tính các nhóm hợp chất tự nhiên dựa vào phương pháp Ciuley đã được cải tiến và sửa đổi (Trần Hùng, 2014). Chiết $10 \mathrm{~g}$ mẫu qua 3 phân đoạn dung môi có độ phân cực tăng dần là ether dầu hỏa, ethanol, nước. Xác định các nhóm hợp chất trong dịch chiết bằng các phản ứng hóa học đặc trưng của từng nhóm.

\subsubsection{Chiết xuất và thu cao toàn phần}

Xà lách xoong thu về rửa sạch, để ráo. Dùng 500 g xà lách xoong tươi chiết với ethanol $70 \%$, ethanol $96 \%$ thu các cao chiết từ dược liệu tươi. Bên cạnh đó, sấy khoảng $1.000 \mathrm{~g}$ xà lách xoong tươi ở $60^{\circ} \mathrm{C}$ trong 12 tiếng, sau đó đem xay nhỏ và chiết với ethanol $(70 \%$ và $96 \%)$ để thu được các cao chiết từ nguyên liệu khô. Các mẫu cao được chiết xuất bằng phương pháp ngâm lạnh ở nhiệt độ phòng trong 72 giờ, có kết hợp khuấy trộn. Dung dịch chiết được lọc qua giấy lọc, cô đuổi dung môi ở $60^{\circ} \mathrm{C}$ đến khi thu được mẫu cao đặc (Nguyễn Kim Phi Phụng, 2007).

Độ ẩm của cao chiết được xác định bằng phương pháp làm mất khối lượng do làm khô, trải cao thành lớp mỏng trên đĩa cân (khoảng $0,5 \mathrm{~g}$ ). Vận hành cân xác định độ ẩm. Ghi nhận độ ẩm. Tiến hành thử trên 3 lần mẫu khác nhau. Lấy kết quả trung bình.

\subsubsection{Khảo sát hàm luợng polyphenol toàn phần}

Trong thành phần thuốc thử Folin-Ciocalteu có phức hợp phosphor-wolfarm-phosphomolybdate. Phức hợp này sẽ bị khử các hợp chất polyphenol tạo thành sản phẩm phản ứng có màu xanh dương, hấp thụ cực đại ở bước sóng $758 \mathrm{~nm}$. Hàm lượng polyphenol có trong mẫu tî̉ lệ thuận với cường độ mẫu. 
Hàm lượng polyphenol được xác định bằng phương pháp Folin-Ciocalteu được mô tả lại theo Marinova et al. (2005) và Pourmord et al. (2006). Pha loãng các mẫu cao chiết bằng methanol để đạt nồng độ $0,5 \mathrm{mg} / \mathrm{mL}$ và dung dịch chuẩn gallic acid nồng độ $10 ; 20 ; 30 ; 40$ và $50 \mu \mathrm{g} / \mathrm{mL}$.

Lấy $0,2 \mathrm{~mL}$ dung dịch chuẩn gallic acid mỗi nồng độ thêm vào $6 \mathrm{~mL}$ nước cất được trộn với 0,5 $\mathrm{mL}$ thuốc thử Folin-Ciocalteau trong 5 phút và 1,5 $\mathrm{mL}$ dung dịch $\mathrm{Na}_{2} \mathrm{CO}_{3} 20 \%$ được thêm vào sau đó, tiếp tục thêm $1,8 \mathrm{~mL}$ nước cất. Để yên trong tối 2 giờ ở nhiệt độ phòng, sau đó đo ở bước sóng 758 nm. Thí nghiệm được lặp lại 3 lần. Giá trị độ hâp thu quang phổ (Abs) được ghi nhận để tiến hành vẽ đường thẳng hiệu chuẩn xác định hàm lượng polyphenol toàn phần trong các mấu cao chiết.

Hàm lượng polyphenol toàn phần chứa trong mẫu cao chiết được đo lường bằng hàm lượng gallic acid đương lượng (GAE) và được tính bằng công thức:

$$
\mathrm{P}=\frac{\mathrm{a} \times \mathrm{V}}{\mathrm{m}} \times \mathrm{N} \times \mathrm{H}
$$

Trong đó: $\mathrm{P}$ : Hàm lượng polyphenol toàn phần (mg GAE/g dược liệu khô)

$\mathrm{a}$ : Giá trị $\mathrm{x}$ từ đường chuẩn gallic acid $(\mu \mathrm{g} / \mathrm{mL})$

V: Thể tích dịch chiết $(\mathrm{mL})$

$\mathrm{m}$ : Khối lượng cao chiết có trong thể tích $(\mathrm{g})$

$\mathrm{N}$ : Độ ẩm cao chiết

H: Hiệu suất chiết cao

\subsubsection{Khảo sát hàm lương flavonoid toàn phần}

Dựa vào sự tương quan giữa độ hấp thu của chất chuẩn quercetin tại bước sóng $510 \mathrm{~nm}$ với nồng độ quercetin $(\mu \mathrm{g} / \mathrm{mL})$ tương ứng trong các điều kiện xác định.

Hàm lượng flavonoid được xác định bằng phương pháp tạo màu với $\mathrm{AlCl}_{3}$ trong môi trường kiềm-trắc quang được mô tả theo Marinova et al. (2005). Methanol được sử dụng để pha loãng mẫu đạt nồng độ $1 \mathrm{mg} / \mathrm{mL}$ và dung dịch flavonoid chuẩn quercetin đạt nồng độ $20 ; 40 ; 60 ; 80$ và $100 \mu \mathrm{g} / \mathrm{mL}$. Lấy $1 \mathrm{~mL}$ dung dịch chuẩn quercetin mỗi nồng độ, thêm vào $4 \mathrm{~mL}$ nước cất lắc đều với $0,3 \mathrm{~mL}$ dung dịch $\mathrm{NaNO}_{2} 10 \%$. Sau 5 phút thêm tiếp $0,3 \mathrm{~mL}$ dung dịch $\mathrm{AlCl}_{3} 10 \%, 2 \mathrm{~mL}$ dung dịch $\mathrm{NaOH} 1 \mathrm{M}$ và 2,4 $\mathrm{mL}$ nước cất được thêm vào 6 phút sau đó. Độ hấp thụ của dung dịch phản ứng được đo ở bước sóng $510 \mathrm{~nm}$, sau 10 phút. Thí nghiệm được lặp lại 3 lần, giá trị độ hấp thu quang phổ (Abs) được ghi nhận và tiến hành vẽ đường thẳng hiệu chuẩn để sử dụng xác định hàm lượng flavonoid toàn phần trong các mẫu cao chiết.
Hàm lượng flavonoid toàn phần chứa trong mẫu cao chiết được đo lường bằng hàm lượng quercetin đương lượng $(\mathrm{QE})$ và được tính bằng công thức:

$$
\mathrm{F}=\frac{\mathrm{c} \mathrm{x} \mathrm{V}}{\mathrm{m}} \times \mathrm{N} \times \mathrm{H}
$$

Trong đó: $\mathrm{F}$ : Hàm lượng flavonoid toàn phần (mg QE/g dược liệu tươi)

c: Giá trị $\mathrm{x}$ từ đường chuẩn quercetin $(\mathrm{mg} / \mathrm{mL})$

V: Thể tích dịch chiết $(\mathrm{mL})$

$\mathrm{m}$ : Khối lượng cao chiết có trong thể tích $(\mathrm{g})$

$\mathrm{N}$ : Độ ẩm của cao chiết

$\mathrm{H}$ : Hiệu suất chiết cao

\subsubsection{Khảo sát hoạt tính kháng oxy hóa}

Khả năng kháng oxy hóa được xác định phương pháp khử gốc tự do DPPH (Chanda \& Dave, 2009). DPPH là gốc tự do ổn định trong methanol, không tự kết hợp để tạo thành nhị phân tử. $\mathrm{DPPH}$ có màu tím nhờ vào điện tử $\mathrm{N}$ chưa ghép đôi nên khi kết hợp với một $\mathrm{H}$ của chất chống oxy hóa tạo thành $\mathrm{DPPH}$ dạng nguyên tử có màu vàng. Sự chuyển đổi dung dịch từ màu tím sang vàng được dùng để xác định khả năng loại gốc tự do có trong mẫu nghiên cứu bằng cách đo độ hấp thu ở bước sóng $517 \mathrm{~nm}$.

Dung dịch DPPH: Pha dung dịch DPPH 0,6 mM trong methanol bằng cách hòa tan $5,915 \mathrm{mg} \mathrm{DPPH}$ với một lượng methanol vừa đủ, sau đó cho vào bình định mức và thêm methanol vừa đủ $25 \mathrm{~mL}$.

Mẫu thủ: Các mẫu cao chiết được hòa tan với methanol để đạt được nồng độ 200, 400,600, 800, $1.000 \mu \mathrm{g} / \mathrm{mL}$, riêng cao chiết MT96 nồng độ 100 , $200,400,600,800$ và đối chứng dương ascorbic acid $(5,10,20,30,40 \mu \mathrm{g} / \mathrm{mL})$. Cho lần lượt cho 3 $\mathrm{mL} \mathrm{MeOH}, 0,5 \mathrm{~mL}$ mẫu thử và $0,5 \mathrm{~mL}$ dung dịch DPPH $0,6 \mathrm{mM}$ vào ống nghiệm, ủ trong tối ở nhiệt độ phòng 30 phút, sau đó đo độ hấp thu ở bước sóng $517 \mathrm{~nm}$. Thí nghiệm được lặp lại 3 lần.

Hoạt tính chống oxy hóa HTCO (\%) được tính theo công thức:

$$
\operatorname{HTCO}(\%)=\frac{\text { (Abs chứng-Abs thử) }}{\text { Abs chứng }} \times 100
$$

Trong đó:

$\mathrm{Abs}_{\text {chứng }}$ : Độ hấp thu của mẫu đối chứng

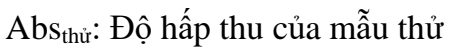

Từ HTCO (\%) và nồng độ mẫu với phần mềm Excel ta được phương trình giữa nồng độ mẫu thử và $\mathrm{HTCO}(\%)$ có dạng $\mathrm{y}=\mathrm{a}(\mathrm{x})+\mathrm{b}$, thế $\mathrm{y}=50$ để suy ra $\mathrm{IC}_{50}$ (khả năng đánh bắt $50 \% \mathrm{DPPH}$ của mẫu). Giá trị $\mathrm{IC}_{50}$ càng thấp tương ứng với $\mathrm{HTCO}$ càng 
cao và ngược lại. Các số liệu kết quả thử nghiệm được biểu thị trung bình của 3 lần đo khác nhau (Nguyễn Thị Thu Hương, 2006).

\subsubsection{Khảo sát khả năng ức chế $\alpha$-glucosidase}

Hoạt tính ức chế $\alpha$-glucosidase in vitro được khảo sát bằng phương pháp mô tả bởi AndradeCetto et al. (2008), Dong et al. (2012) và Kwon et al. (2008) với một số hiệu chỉnh.

Chuẩn bị mẫu nghiên cứu: Cân khối lượng cao chiết và dựa vào độ ẩm để quy ra khối lượng cao khô. Các mẫu cao chiết được hòa tan bằng nước cất. Các cao chiết MT70, MK70, MT96, MK96 được khảo sát ở các nồng độ phản ứng $750 \mu \mathrm{g} / \mathrm{mL}$ để tìm giá trị phần trăm ức chế $\alpha$-glucosidase ( $\mathrm{I} \%)$. Acarbose được sử dụng làm đối chứng dương và khảo sát ở các nồng độ $375 \mu \mathrm{g} / \mathrm{mL}$.

Tiến hành khảo sát trên đĩa 96 giếng: Chuẩn bị các dung môi hóa chất cần thiết và tiến hành khảo sát trên đĩa 96 giếng, mỗi nồng độ 3 lần lặp lại với đối chứng dương. Hỗn hợp gồm $60 \mu \mathrm{L}$ dung dịch chứa mẫu và $50 \mu \mathrm{L}$ dung dịch đệm phosphate $0,1 \mathrm{M}$ (pH 6,8) có chứa dung dịch $\alpha$-glucosidase $(0,2$ $\mathrm{IU} / \mathrm{mL}$ ) được ủ trong các giếng của đĩa 96 ở nhiệt độ $37^{\circ} \mathrm{C}$ trong 10 phút. Sau đó, thêm $50 \mu \mathrm{L}$ dung dịch $p$-NPG được pha trong dung dịch đệm phosphate 0,1 $\mathrm{M}(\mathrm{pH} 6,8)$ vào từng giếng và tiếp tục ủ trong 20 phút. Sau đó đo chỉ số quang phổ kế và được ghi lại ở bước sóng $405 \mathrm{~nm}$ bằng máy đọc vi đĩa model Elx808 (Biotek, USA) và so sánh với một mẫu chứng chứa $60 \mu \mathrm{L}$ dung dịch đệm thay cho mẫu thử.

Khả năng ức chế $\alpha$-glucosidase được đánh giá trên phần trăm lượng $\alpha$-glucosidase bị ức chế $\mathrm{I} \%$. Phần trăm ức chế được xác định theo công thức:

Khả năng ức chế $\alpha$-glucosidase được đánh giá trên phần trăm lượng $\alpha$-glucosidase bị ức chế $\mathrm{I} \%$. Phần trăm ức chế được xác định theo công thức:

$$
\mathrm{I}(\%)=\frac{\mathrm{A}_{0}-\mathrm{A}_{\mathrm{s}}}{\mathrm{A}_{\mathrm{o}}} \quad \mathrm{x} 100
$$

Trong đó:

$\mathrm{A}_{\mathrm{o}}$ là độ hấp thu của mẫu đối chứng.

$\mathrm{A}_{\mathrm{s}}$ là độ hấp thu của mẫu khảo sát.

I (\%) là phần trăm ức chế.

Từ $\mathrm{I} \%$ và nồng độ mẫu tiến hành vẽ đường cong phi tuyến. Dựa vào đường cong phi tuyến, tính được $\mathrm{IC}_{50}$ (nồng độ mẫu mà tại đó ức chế $50 \%$ hoạt tính của $\alpha$-glucosidase) bằng cách thay $\mathrm{y}=50$ vào phương trình đường cong phi tuyến logarith có dạng $\mathrm{y}=\mathrm{a} \ln (\mathrm{x})+\mathrm{b}$. Mẫu có hoạt tính ức chế càng mạnh khi giá trị $\mathrm{IC}_{50}$ càng nhỏ. Thông qua $\mathrm{IC}_{50}$ có thể đánh giá và so sánh hoạt tính ức chế $\alpha$-glucosidase giữa các mẫu cao chiết với nhau và so với đối chứng dương.

\subsubsection{Khảo sát hoạt tính gây độc bằng phwơng pháp Sulforhodamin B (SRB)}

Dòng tế bào ung thư vú (MCF-7) được nuôi cấy trong môi trường E'MEM có bổ sung L-glutamin (2 $\mathrm{mL})$, HEPES $(20 \mathrm{mM})$, amphotericin $\mathrm{B}(0,025$ $\mu \mathrm{g} / \mathrm{mL})$, penicillin $\mathrm{G}(100 \mathrm{UI} / \mathrm{mL})$, streptomycin $(100 \mu \mathrm{g} / \mathrm{mL}), 10 \%(\mathrm{v} / \mathrm{v})$ huyết thanh bào thai bò FBS và ủ ở $37^{\circ} \mathrm{C}, 5 \% \mathrm{CO}_{2}$. Tế bào đơn được cấy trên đĩa nuôi cấy 96 giếng với mật độ $10^{4}$ tế bào/giếng. Sau 24 giờ, quần thể tế bào tiếp tục được ủ với chất khảo sát ở các nồng độ trong 48 giờ. Sau đó, protein tổng từ tế bào thử nghiệm được cố định bằng dung dịch trichloroaceic acid $50 \%$ và nhuộm với dung dịch SRB $0,2 \%$. Kết quả được đọc bằng máy ELISA reader ở 2 bước sóng $492 \mathrm{~nm}$ và $620 \mathrm{~nm}$. $\mathrm{IC}_{50}$ được xác định bằng cách sử dụng phần mềm Prism với phương pháp hồi quy không tuyến tính đa thông số và $\mathrm{R}^{2}>0,95$ (Nguyễn Thái Hoàng Tâm và ctv., 2007; Nguyen and Ho, 2016).

Sau khi có giá trị mật độ quang ở bước sóng 492 $\mathrm{nm}$ và $620 \mathrm{~nm}$ (ký hiệu là $\mathrm{OD}_{492}$ và $\left.\mathrm{OD}_{620}\right)$. Kết quả được tính toán như sau:

- Tính $\mathrm{OD}_{492}\left(\right.$ hoặc $\left.\mathrm{OD}_{620}\right)=\mathrm{OD}_{\mathrm{tb}}-\mathrm{OD}_{\text {blank }}(1)$

(2)

- Tính giá trị $\mathrm{OD}_{\text {tn }}\left(\right.$ hoặc $\left.\mathrm{OD}_{\mathrm{c}}\right)=\mathrm{OD}_{492}-\mathrm{OD}_{620}$

- Tính tỉ lệ (\%) gây độc tế bào theo công thức:

$\mathrm{I}(\%)=\left(1-\frac{\mathrm{ODtn}}{\mathrm{ODc}}\right) \times 100$

Với:

$\mathrm{OD}_{\mathrm{tb}}$ : Giá trị $\mathrm{OD}$ của giếng có chứa tế bào bào)

OD blank: Giá trị OD của giếng blank (không có tế

$\mathrm{OD}_{\mathrm{tn}}$ : Giá trị $\mathrm{OD}$ của mẫu thử tính từ công thức (1) và (2)

$\mathrm{OD}_{\mathrm{C}}$ : Giá trị $\mathrm{OD}$ của mẫu chứng (control) tính từ công thức (1) và (2).

2.2.8. Khảo sát sụ tương quan giũa các kết quả

Các số liệu được phân tích, xử lí thống kê và khảo sát tương quan bằng phần mềm SPSS 16.0.

\section{KẾT QUẢ VÀ THẢO LUẬN}

Kết quả về hiệu suất chiết cao và độ ẩm của các cao chiết được từ nguyên liệu ban đầu là xà lách xoong tươi $(500 \mathrm{~g})$ và xà lách xoong khô $(100 \mathrm{~g})$ với dung môi ethanol ở 2 nồng độ ( $70 \%$ và ethanol $96 \%)$ được ký hiệu và thể hiện qua Bảng 1. 
Bảng 1. Hiệu suất chiết và độ ẩm của các mẫu cao chiết

\begin{tabular}{lcrr}
\hline Mẫu & Ký hiệu & Hiệu suất chiết (\%) & Độ ẩm cao chiết (\%) \\
\hline Xà lách xoong tươi (ethanol 70\%) & MT70 & 3,20 & 10,26 \\
Xà lách xoong tươi (ethanol 96\%) & MT96 & 2,17 & 12,62 \\
Xà lách xoong khô (ethanol 70\%) & MK70 & 34,95 & 11,83 \\
Xà lách xoong khô (ethanol 96\%) & MK96 & 26,87 & 8,63 \\
\hline
\end{tabular}

\subsection{Thành phần hóa học có trong các mẫu xà lách xoong}

Kết quả sơ bộ thành phần hóa học thể hiện ở Bảng 2 cho thấy hai loại xà lách xoong (tươi, khô) đều chứa chất béo, carotenoid, acid hữu cơ, nhiều polyphenol và flavonoid; riêng xà lách xoong khô có nhiều polyuronid và xà lách xoong tươi còn có tinh dầu, proanthocyanidin. Nhóm hợp chất polyphenol, đặc biệt là flavonoid được biết đến với các tác dụng tốt cho sức khỏe con người như kháng oxy hóa, kháng viêm, hạn chế tăng lipid máu, ngăn ngừa hoặc làm chậm tiến trình một số bệnh như ung thư, tim mach... (Durazzo et al., 2019; Panche et al., 2016); qua đó có thể thấy xà lách xoong có chứa các nhóm hợp chất có nhiều tiềm năng sinh học.

\section{Bảng 2. Kết quả sơ bộ thành phần hóa học của xà lách xoong}

\begin{tabular}{lcc}
\hline Nhóm họ̣p chất & $\begin{array}{c}\text { Xà lách } \\
\text { xoong tươi }\end{array}$ & $\begin{array}{c}\text { Xà lách } \\
\text { xoong khô }\end{array}$ \\
\hline Chất béo & + & + \\
Carotenoid & + & + \\
Tinh dầu & + & - \\
Triterpenoid tự do & + & - \\
Anthraquinon & + & - \\
Flavonoid & + & + \\
Proanthocyanidin & + & - \\
Polyphenol & + & + \\
Triterpenoid thủy phân & - & - \\
Acid hữu cơ & + & + \\
Hơp chất polyuronid & - & + \\
\hline
\end{tabular}

\subsection{Hàm lượng polyphenol toàn phần và} flavonoid toàn phần

Kết quả hàm lượng polyphenol toàn phần (TPC) và flavonoid toàn phần (TFC) của các mẫu cao chiết được thể hiện ở Bảng 3.

Nhìn chung, hàm lượng polyphenol toàn phần trong các mẫu khảo sát cao thì lượng flavonoid thu cao tương ứng, nổi bật nhất là cao chiết MK70. Riêng mẫu cao chiết MK96 có hàm lượng polyphenol thu được chỉ thấp hơn MK70 nhưng lượng flavonoid thu được là thấp nhất $(1,99 \pm 0,307$ $\mathrm{mg} \mathrm{QE} / \mathrm{g}$ dược liệu tươi). Hàm lượng flavonoid khi chiết xuất với dung môi ethanol 70 cao hơn ethanol $96 \%$.

Bên cạnh đó, đa số các cao chiết từ dược liệu khô có hàm lượng polyphenol và flavonoid toàn phần cao hơn các chiết từ dược liệu tươii, có thể do quá trình loại nước để làm khô dược liệu giúp hàm lượng polyphenol và flavonoid dược liệu được cô đặc hơn nhiều (Đỗ Huy Bích, 2006; Lizette, 2016). Ngoài ra, hàm lượng polyphenol và flavonoid toàn phần khi chiết xuất bằng dung môi ethanol $70 \%$ thu được cao hơn so với ethanol 96\%, tương tự với kết quả nghiên cứu của Rahman et al (2013) thực hiện trên cây Cà dại hoa trắng (Solanum torvum) cũng kết luận dung môi có độ phân cực càng cao, hàm lượng polyphenol và flavonoid toàn phần thu được càng nhiều. Điều này cho thấy hàm lượng chất chiết được phụ thuộc vào nhiều yếu tố như bản chất dược liệu, dung môi và điều kiện chiết xuất (Mohsen et al., 2009).

\section{Bảng 3. Hàm lượng polyphenol toàn phần và flavonoid toàn phần trong các mẫu cao chiết}

\begin{tabular}{crr}
\hline Mẫu cao chiết & $\begin{array}{r}\text { TPC } \\
\text { (mg GA/g nguyên liệu tươi) }\end{array}$ & $\begin{array}{r}\text { TFC } \\
\text { (mg QE/g nguyên liệu tươi) }\end{array}$ \\
\hline MT70 & $3,53 \pm 0,021^{\mathrm{c}}$ & $3,21 \pm 0,081^{\mathrm{a}}$ \\
MT96 & $2,72 \pm 0,028^{\mathrm{d}}$ & $2,69 \pm 0,093^{\mathrm{b}}$ \\
MK70 & $6,01 \pm 0,177^{\mathrm{a}}$ & $3,33 \pm 0,049^{\mathrm{a}}$ \\
MK96 & $4,77 \pm 0,081^{\mathrm{b}}$ & $1,99 \pm 0,307^{\mathrm{c}}$ \\
\hline
\end{tabular}

(1): Các giá trị được xác định dụa vào phuơng trình đường chuẩn của gallic acid $\left(y=0,0064 x-0,0018 ; r^{2}=0,9986\right)$.

(2): Các giá trị được xác định dựa vào phuoong trình đưòng chuẩn của quercetin $\left(y=0,0005 x+0,0002 ; r^{2}=0,9924\right)$.

Trong cùng một cột, các số trung bình theo sau bởi một hoặc nhũng chũ cái giống nhau thì khác biệt không có ý nghĩa thống kê ở múc ý nghĩa 5\% bằng phép thử Tukey. 


\subsection{Khả năng kháng oxy hóa của các mẫu cao chiết xà lách xoong}

Kết quả hoạt tính kháng oxy hóa thể hiện qua giá trị $\mathrm{IC}_{50}$ của các mẫu cao chiết được thể hiện ở Bảng 4.

Bảng 4. Khả năng khử $50 \%$ gốc tự do DPPH

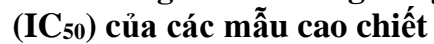

\begin{tabular}{lr}
\hline Mẫu & IC $_{\mathbf{5 0}}(\boldsymbol{\mu g} \mathbf{g} / \mathbf{m L})$ \\
\hline MT70 & $580,75 \pm 0,0^{\mathrm{b}}$ \\
MT96 & $493,40 \pm 0,007^{\mathrm{b}}$ \\
MK70 & $847,78 \pm 0,006^{\mathrm{c}}$ \\
MK96 & $960,83 \pm 0,006^{\mathrm{d}}$ \\
Vitamin C & $24,00 \pm 0,002^{\mathrm{a}}$ \\
\hline
\end{tabular}

Trong cùng môt cột, các số trung bình theo sau bởi một hoặc những chũ cái giống nhau thì khác biệt không có ý nghĩa thống kê ở mức ý nghĩa 5\% bằng phép thư Tukey.

Kết quả trình bày ở Bảng 4 cho thấy cả 4 mẫu cao chiết đều thể hiện thể hiện khả năng khử-gốc tự do $\mathrm{DPPH}$, tuy nhiên, khả năng này vẫn thấp nhiều so với đối chứng vitamin $\mathrm{C}$ (ít nhất 20 lần). Ở khảo sát này, các mẫu cao được chiết xuất bằng dung môi ethanol $70 \%$ cũng thể hiện hoạt tính kháng oxy hóa tốt hơn so với cao chiết từ dung môi ethanol $96 \%$. Trong đó, các cao chiết từ xà lách xoong tươi có khả năng kháng oxy hóa tôt hơn so với xà lách xoong khô (khoảng 2 lần), tương tự với nghiên cứu thực hiện trên các cao chiết từ dược liệu khô và dược liệu tươi của Capecka et al. (2005) trên họ hoa môi (Lamiaceae) và nghiên cứu trên 8 loại thảo mộc (húng quế, ớt, ngò, thì là, tỏi, gừng, sả, kinh giới và mùi tây) của Henning et al. (2011). Như vậy, kết quả thu được ở khảo sát này cũng cho thấy sự khác biệt về hoạt tính chống oxy của các mẫu thử nghiệm phụ thuộc vào bản chất dược liệu. Quá trình làm khô mẫu (sấy ở $60^{\circ} \mathrm{C}$ ) các vitamin (đặc biệt là ascorbic acid) và các hoạt chất khác có thể đã bị biến đổi cấu trúc, mất hoạt tính hoặc giảm nồng độ so với dược liệu tươi, ngoài ra, những chất không bền, nhạy cảm với quá trình oxy hóa, nhiệt độ (Alfredo et al., 2013).

\subsection{Khả năng ức chế $\alpha$-glucosidase của các mẫu cao chiết xà lách xoong}

Phần trăm ức chế $\alpha$-glucosidase của các mẫu cao xà lách xoong ở nồng độ $750 \mu \mathrm{g} / \mathrm{mL}$ được thể hiện qua Bảng 5.

Nhiều nghiên cứu đã chứng minh các cao chiết thực vật có khả năng ức chế $\alpha$-glucosidase phụ thuộc vào hàm lượng polyphenol, trong đó flavonoid là một nhóm chính của các hợp chất polyphenol thể hiện khả năng này (Đái Thị Xuân Trang và ctv., 2019; Kim et al., 2000). Nhìn chung, ở nồng độ 750 $\mu \mathrm{g} / \mathrm{mL}$, khả năng ức chế $\alpha$-glucosidase in vitro của các mẫu cao tương đối thấp $(<20 \%)$ nên không thực hiện tiếp thử nghiệm để xác định $\mathrm{IC}_{50}$. Tuy nhiên, kết quả cũng cho thấy các cao chiết từ xà lách xoong còn tồn tại các hoạt chất có khả năng này, cần phải phân lập và xác định.

Bảng 5. Khả năng ức chế $\alpha$-glucosidase của 4 cao thử nghiệm và acarbose

\begin{tabular}{lrr}
\hline Mẫu & $\begin{array}{r}\text { Nồng độ phản } \\
\text { ứng }(\mu \mathrm{g} / \mathrm{mL})\end{array}$ & $\mathbf{I \%}$ \\
\hline MT70 & 750 & $14,41^{\mathrm{b}}$ \\
MT96 & 750 & $12,99^{\mathrm{b}}$ \\
MK70 & 750 & $15,38^{\mathrm{b}}$ \\
MK96 & 750 & $17,52^{\mathrm{b}}$ \\
Acarbose & 375 & $66,31^{\mathrm{a}}$ \\
\hline
\end{tabular}

Ghi chú: Trong cùng một cột, các số trung bình theo sau bởi một hoặc nhũng chũ cái giống nhau thì khác biệt không có ý nghĩa thống kê ở mức ý nghĩa 5\% bằng phép thi Tukey.

Các nghiên cứu trước đây đã chứng minh tác dụng ức chế $\alpha$-glucosidase của xà lách xoong là do roseoside, pinoresinol và các glycosid. Tuy nhiên, roseoside, pinoresinol là những chất dễ bị phân hủy bởi nhiệt độ, ảnh hưởng bởi quá trình oxy hóa trong quá trình phơi sấy dược liệu, cô cao chiết. Bên cạnh đó, các mẫu cao chiết xà lách xoong tươi tuy dùng nguyên liệu tươi nhưng qua quá trình chiết suất và cô cao thì những hợp chất nêu trên cũng bị phân hủy và giảm nồng độ đáng kể. Vì vậy khả năng ức chế $\alpha$-glucosidase của các cao chiết trong thử nghiệm thấp hơn nhiều lần so với dịch ép của cây (Spinola et al., 2016; Yang et al., 2016).

\subsection{Kết quả về khả năng gây độc tế bào MCF-7 của các mẫu cao chiết xà lách xoong}

Ở nồng độ $500 \mu \mathrm{g} / \mathrm{mL}$, phần trăm gây độc tế bào ung thư của các mẫu cao thử nghiệm trên dòng tế bào ung thư vú MCF-7 được xác định bằng phương pháp SRB được thể hiện qua Bảng 6 .

Bảng 6. Khả năng ức chế tế bào ung thư vú (MCF-7) của các mẫu thử nghiệm

\begin{tabular}{lrr}
\hline Mẫu & $\begin{array}{r}\text { Nồng độ } \\
(\boldsymbol{\mu g} / \mathbf{m L})\end{array}$ & $\begin{array}{c}\text { Phần trăc tệ bà gây } \\
\text { đọ }\end{array}$ \\
\hline MT70 & 500 & $19,65 \pm 8,75 \mathrm{bc}$ \\
MT96 & 500 & $32,44 \pm 5,17 \mathrm{~b}$ \\
\hline MK70 & 500 & $21,22 \pm 2,62 \mathrm{bc}$ \\
MK96 & 500 & $10,74 \pm 4,85 \mathrm{c}$ \\
Camptothecin & 0,01 & $55,65 \pm 5,81 \mathrm{a}$ \\
\hline
\end{tabular}

Ghi chú: Trong cùng một cột, các số trung bình theo sau bởi một hoặc những chũ cái giống nhau thì khác biệt 
không có ý nghĩa thống kê ở mức ý nghĩa $5 \%$ bằng phép thư Tukey.

Ở nồng độ $500 \mu \mathrm{g} / \mathrm{mL}$, các cao chiết đều có khả năng gây độc tế bào ung thư vú, mạnh nhất là MT96 với phần trăm gây độc tế bào là $32,44 \%$, tuy nhiên, tỉ lệ tế bào chết dưới $50 \%$ nên đề tài không thực hiện tiếp thử nghiệm xác định $\mathrm{IC}_{50}$.

Sự tương quan giữa các đại lượng khảo sát trong nghiên cứu này được xác định và trình bày ở Bảng 7.

Bảng 7. Hệ số tương quan giữa hàm lượng TPC, TFC với các hoạt tính sinh học

\begin{tabular}{lccccc}
\hline & TPC & TFC & $\mathbf{1 / I C}_{\mathbf{5 0}}$ & $\mathbf{I \%}$ & Khả năng gây độc tế bào MCF-7 \\
\hline Polyphenol & 1 & 0,126 & $-0,886^{* *}$ & 0,337 & $-0,452$ \\
Flavonoid & & 1 & 0,304 & $-0,657^{*}$ & 0,364 \\
$1 / \mathrm{IC}_{50}$ & & & 1 & $-0,587^{*}$ & $0,696^{*}$ \\
I\% & & & & 1 & $-0,440$ \\
Khả năng gây độc tế bào & & & & & 1
\end{tabular}

Ghi chú: Giá trị tuoong quan có ý nghĩa thống kê ở mức ý nghĩa 1\% (**) và 5\% (*) thông qua phép so sánh tuoong quan Pearson.

Dựa vào kết quả ở Bảng 7 nhận thấy có sự tương quan nghịch giữa hàm lượng polyphenol với giá trị $1 / \mathrm{IC}_{50}(\mathrm{r}=0,830$; ở mức ý nghĩa $\mathrm{p}<0,05)$ có nghĩa là hàm lượng polyphenol toàn phần có trong các mẫu thử nghiệm không là tác nhân chính trong việc khử gốc tự do DPPH, mà có thể do các nhóm hoạt chất khác có trong cây xà lách xoong quyết định. Hàm lượng flavonoid toàn phần có trong các mẫu cao chiết thể hiện tương quan thuận với giá trị $1 / \mathrm{IC}_{50}$, tuy nhiên sự tương quan này lại không có ý nghĩa thống kê. Việc không tìm thấy mối tương quan chặt chẽ giữa hàm lượng polyphenol toàn phần và flavonoid toàn phần với khả năng kháng oxy hóa có thể là do phản ứng không chọn lọc của các phương pháp định lượng được sử dụng (Alfredo et al., 2013).

Bên cạnh đó, hàm lượng flavonoid toàn phần và hệ số $1 / \mathrm{IC}_{50}$ thể hiện mối tương quan nghịch với khả năng ức chế chế $\alpha$-glucosidase (ở mức ý nghĩa $\mathrm{p}<0,05 \%$ ), điều này cho thấy khi hàm lượng flavonoid càng cao và khả năng kháng oxy hóa càng mạnh thì khả năng ức chế $\alpha$-glucosidase càng mạnh. Điều này đã được chứng minh qua các nghiên cứu trên một số loại flavonoid của Kamalakkannan \& Prince (2006) và Wang et al. (2010) về tác dụng kháng oxy hóa và hạ đường huyết in vivo. Các flavonoid có khả năng ức chế $\alpha$-glucosidase là do cấu trúc vòng $\mathrm{C}$ không bão hòa, 3-OH, 4-CO và liên kết của vòng $B$ ở vị trí số 3 . Khi tăng nhóm hydroxyl trên vòng $\mathrm{B}$ trong cấu trúc các flavonoid thì hoạt tính ức chế $\alpha$-glucosidase tăng lên đáng kể (Đái Thị Xuân Trang, 2019; Tadera et al., 2006).

Ngoài ra, giá trị $1 /$ IC 50 còn thể hiện sự tương quan nghịch với $\mathrm{I} \%(\mathrm{r}=0,639 ; \mathrm{p}<0,05 \%)$ và tương quan thuận với khả năng gây độc tế bào MCF-7 $(\mathrm{r}=0,680 ; \mathrm{p}<0,05 \%)$. Có thể thấy, ở xà lách xoong những hoạt chất có tác dụng kháng oxy cũng có khả năng gây độc tế bào. Theo Leee \& Cho (2008) và
Cavill (2012) xà lách xoong tươi chứa một lượng đáng kể gluconasturtiin là tiền chất glucosinolate của PEITC (phenethyl isothiocyanate), thông qua khả năng làm cạn kiệt glutathion trong tế bào ung thư vú PEITC làm cho tế bào ung thư vú bị tổn thương do bức xạ, ngoài ra PEITC còn là tác nhân quan trọng gây ra quá trình chết theo lập trình (apoptosis) của các tế bào ung thư vú dòng MCF-7. Tuy nhiên, PEITC hoặc các isothiocyanate khác thường không được tìm thấy trong chiết xuất do tính chất dễ bay hơi, cũng như quá trình chiết xuất làm bất hoạt myrosinase chuyển đổi tiền chất glucosinolate thành isothiocyanate phản ứng (Cavill, 2012; Giallourou et al., 2019; Lee \& Cho, 2008). Như vậy, khả năng gây độc tế bào ung thư vú (MCF-7) của các cao chiết trong trường hợp này có thể do nhóm chất nào đó có trong các cao chiết xà lách xoong. Bằng phương pháp sắc ký lỏng hiệu năng cao, các nghiên cứu trước đây đã xác định được xà lách xoong có chứa một số hợp chất có tác dụng gây độc tế bào ung thư như sinapic acid, ferulic acid, caffeic acid, và gallic acid,...(Niciforovic \& Abramovic, 2014; Ozen, 2009; Zed, 2015). Vì vậy, cần phân lập và xác định các nhóm chất tiềm năng có trong cây, thử nghiệm trên các dòng tế bào ung thư khác nhằm làm rõ hơn khả năng và ứng dụng của cây xà lách xoong trong việc ngăn ngừa sự hình thành, phát triển và tiêu diệt các tế bào ung thư.

\section{KẾT LUẬN}

Kết quả nghiên cứu cho thấy các mẫu cao chiết xà lách xoong đều thể hiện khả năng chống oxy hóa, mẫu xà lách xoong tươi có khả năng kháng oxy hóa tốt hơn mẫu xà lách xoong khô. Nhìn chung các mẫu cao chiết xà lách xoong tươi có tiềm năng sinh học cao hơn xà lách xoong khô, việc nghiên cứu trên 
dịch ép của cây cũng như phân lập các hợp chất tiềm năng có trong cây cần được nghiên cứu thêm.

\section{TÀI LIỆU THAM KHẢO}

Alfredo, A., Rosa, C., Eduardo, A.S.R., \& Saavedra, M.J. (2013). Phytochemical characterization and antioxidant properties of baby-leaf watercress produced under organic production system. Journal CyTA - Journal of Food, 11, 343-351.

Andrade-Cetto, A., Becerra-Jiménez, J., \& CárdenasVázquez, R. (2008). Alfa-glucosidase-inhibiting activity of some Mexican plants used in the treatment of type 2 diabetes. Journal of Ethnopharmacology, 116(1), 27-32.

Capecka, E., Mareczek, A., \& Leja, M. (2005). Antioxidant activity of fresh and dry herbs of some Lamiaceae species. Food Chemistry, 93, 223-226.

Cavill, B.E. (2012). In vitro analysis of potential anticancer effects associated with watercress. The degree of Doctor of Philosophy. University of Southampton.

Chanda, S., \& Dave, R. (2009). In vitro models for antioxidant activity and some medicinal plants possessing antioxidant properties. African Journal of Microbiology Research, 3, 981-996.

Đái Thị Xuân Trang, Nguyễn Thị Thùy Oanh, Trần Chí Linh, Lê Thanh Phương Thảo, Trần Thanh Mến \& Nguyễn Trọng Tuân (2019). Đánh giá khả năng kháng oxy hóa, ức chế enzyme $\alpha$ amylase và $\alpha$-glucosidase của các cao chiết từ lá cây Núc nác (Oroxylum indicum L.). Tạp chí Khoa học Trưòng Đại học Cần Tho, 55, 9-36.

Đỗ Huy Bích (2009). Cây thuốc và động vật làm thuốc ở Việt Nam tập 1 (trang 319-320). Nhà xuất bản Khoa học và Kỹ Thuật.

Dong, H.Q., Li, M., Zhu, F., Liu, F.L., \& Huang, J.B. (2012). Inhibitory potential of trilobatin from Lithocarpus polystachyus Rehd against $\alpha$ glucosidase and $\alpha$-amylase linked to type 2 diabetes. Food Chemistry, 130(2), 261-266.

Durazzo, A., Lucarini, M., Souto, E.B., Cicala, C., Caiazzo, E., Izzo, A.A., Novellino, E., \& Santini, A., (2019). Polyphenols: A concise overview on the chemistry, occurrence, and human health. Phytotheraphy research, 33, 2221-2243.

Giallourou, N.S., Rowland, I.R., Rothwell, T.D., Packham, G., Commane, D.M., \& Swann, J.R. (2019). Metabolic targets of watercress and PEITC in MCF-7 and MCF-10A cells explain differential sensitisation responses to ionising radiation. European Journal of Nutrition, 58, 2377-2391.

Henning, S.M., Zhang, Y., Seeram, N.P., Lee, R.P., Wang, P., Bowerman, S., \& Heber, D. (2011). Antioxidant capacity and phytochemical content of herbs and spices in dry, fresh and blended herb paste form. International Journal of Food Sciences and Nutrition, 62, 219-225.

Hua, Q.D., Mei, L., Feng, Z., Fu, L.L., \& Jia, B.H. (2012). Inhibitorypotential of trilobatin from Lithocarpus polystachyus Rehd against $\alpha$ glucosidase and $\alpha$-amylase linked to type 2 diabetes. Food Chemistry, 130, 261-266.

Imtiaz, B., Fozia, Waheed, A., Rehman, A., Ullah, H., Iqbal, H., Wahab, A., Almas, M., \& Ahmad, I. (2012). Antimicrobial activity of Malva neglecta and Nasturtium microphyllum. International Journal of Research in Ayurveda and Pharmacy, 3, 808-810.

Kamalakkannan, N., \& Prince, P.S.M. (2006). Rutin improves the antioxidant status in streptozotocininduced diabetic rat tissues. Molecular and Cellular Biochemistry, 293, 211-219.

Kim, J.S., Kwon, C.S., \& Sou, K.H. (2000). Inhibition of alpha-glucosidase and amylase by luteolin, a flavonoid. Biosce Biotechnol Biochem, 64, 2458-2461.

Kwon, Y.I., Apostolidis, E., \& Shetty, K. (2008). Inhibitory potential of wine and tea against $\alpha$ amylase and $\alpha$-glucosidase for management of hyperglycemia linked to type 2 diabetes. Journal of Food Biochemistry, 32(1), 15-31.

Lee, J.W., \& Cho, M.K. (2008). Phenethyl isothiocyanate induced apoptosis via down regulation of $\mathrm{Bcl}-2 / \mathrm{XIAP}$ and triggering of the mitochondrial pathway in MCF-7 cells. Archives of Pharmacal Research, 31, 1604-1612

Lizette B. (2016). Benefits Of Watercress: Lower blood pressure and 5 other conditions it can alleviate.

https://www.medicaldaily.com/benefitswatercress-lower-blood-pressure-and-6-otherconditions-it-can-399859

Marinova D., Ribarova F., \& Atanassova M. (2005). Total phenolics and total flavonoids in Bulgarian fruits and vegetables. Journal of the University of Chemical Technology and Metallurgy, 40, 255-260.

Mohsen, S.M., \& Ammar, A.S.M. (2009). Total phenolic contents and antioxidant activity of corn tassel extracts. Food Chemistry, 112, 595-598.

Nguyễn Kim Phi Phụng (2007). Phương pháp cô lập hợp chất hữu cơ (trang 28-54). Nhà xuất bản Đại học Quốc gia TP Hồ Chí Minh.

Nguyễn Thái Hoàng Tâm, Nguyễn Thụy Vy, Tất Tố Trinh, Nguyễn Thị Tuyết Giang. Nguyễn Ngọc Hạnh \& Hồ Huỳnh Thùy Dương (2007). Chuẩn hóa thử nghiệm Sulforhodamin $\mathrm{B}$ (SRB) để xác định tính gây độc tế bào của hợp chất tự nhiên. Hội nghị khoa học toàn quốc 2007 - Nghiên cứu cơ bản trong khoa học sự sống (trang 809). 
Nguyễn Thị Thu Hương, Đỗ Trung Đàm \& Viện Dược Liệu (2006). Phương pháp nghiên cứu tác dụng dược lý của thuốc từ thảo dược (trang 279286). Nhà xuất bản Khoa Học và Kỹ thuật.

Nguyen, M.N.T \& Ho, H.T.D. (2016). Selective cytotoxicity of a Vietnamese traditional formula, Nam Dia long, against MCF-7 cells by synergistic effects. BMC Complementary and Alternative Medicine, 16, 202-236.

Niciforovic, N., \& Abramovic, H. (2014). Sinapic acid and its derivatives: Natural sources and bioactivity. Comprehensive reviews in Food Science and Food Safety, 13, 34-51.

Ozen, T. (2009). Investigation of antioxidant properties of Nasturtium officinale (watercress) leaf extracts. Acta Poloniae Pharmaceutica and Drug Research, 66, 187-193.

Panche, A. N., Diwan, A.D., \& Chandra S.R. (2016). Flavonoids: An overview. Jounal of Nutrional Science, 5, 1-15.

Phạm Hoàng Hộ (2003). Cây cỏ Việt Nam tập 1 (trang 605). Nhà xuất bản Trẻ.

Pourmord F., Hosseinimehr S.J., \& Shahabimajd N. (2006). Antioxidant activity, phenol and flavonoid contents of some selected Iranian medicinal plants. African Journal of Biotechnolog, 5, 1142-1145.

Rahman, N., Marliyati, S.A., Damanik, M.R.M., \& Anwar, F. (2013). Antioxidant activity and total phenol content of ethanol extract Takokak fruit (Solanum torvum). Pakistan Journal of Nutritio, 12, 973-977.
Rasheed, S., Khuroo, A.A., Ganie, A.H., Mehraj, G., Dar, T.U.H., \& Dar, G.H. (2018). Correct taxonomic delimitation of Nasturtium microphyllum Rchb. from Nasturtium officinale R. Br. (Brassicaceae) in Kashmir Himalaya, India. Journal of Asia-Pacific Biodiversity, 11, 154-157.

Sepahi, S., Ghorani-Azam, A., Sepahi, S., Asoodeh, A., \& Rostami, S. (2014). In vitro study to evaluate antibacterial and non-haemolytic activities of four Iranian medicinal plants. West Indian Mededical Journal, 63, 289-293.

Spinola, V., Pinto, J., \& Castilho, P.C. (2016). In vitro studies on the effect of watercress juice on digestive enzymes relevant to type 2 diabetes and obesity and antioxidant activity. Journal of Food Biochemistry, 41, 1-8.

Tadera, K., Minami, Y., Takanatsu, K., \& Matsuoka, T. (2006). Inhibition of $\alpha$-glucosidase and $\alpha$ amylase by flavonoids. Journal of Nutritional Science and Vitaminology, 52(2), 149-153.

Trần Hùng (2014). Giáo trình Phương pháp nghiên cứu dược liệu (trang 25-49). Bộ môn Dược liệu. Khoa Dược. Trường Đại học Y Dược TP Hồ Chí Minh.

Wang, H., Du, Y.J., \& Song, H.C. (2010). Alphaglucosidase and $\alpha$-amylase inhibitory activities of guava leaves. Food Chemistry, 123, 6-13.

Yang, D., Liang, J., Xie, H., \& Wei, X. (2016). Norsesquiterpenoids and triterpenoids from strawberry cv. Falandi. Food Chemisry, 203, 67-72.

Zed, A. (2015). Phenolic profile and antioxidant potential of wild watercress (Nasturtium officinale L.). SpringerPlus, 4, 714. 